\title{
The Variations of the Subclavian Artery and Its Branches
}

\author{
By \\ Ahmet H. YÜCEL, Emine KIZILKANAT and Cengiz Ö. ÖZDEMIR \\ Department of Anatomy, Faculty of Medicine, Çukurova University, 01330 Balcal, Adana Turkey \\ - Received for Publication, June 19, 1999 -
}

Key Words: Subclavian artery, Vertebral artery, Arterial variation

\begin{abstract}
Summary: This study reports important variations in branches of the subclavian artery in a singular cadaver. The origin of the left vertebral artery was from the aortic arch. On the right side, no thyrocervical trunk was found. The two branches which normally originate from the thyrocervical trunk had a different origin. The transverse cervical artery arose directly from the subclavian artery and suprascapular artery originated from the internal thoracic artery. This variation provides a short route for posterior scapular anastomoses. An awareness of this rare variation is important because this area is used for diagnostic and surgical procedures.
\end{abstract}

The subclavian artery, the main artery of the upper extremity, also gives off the branches which supply the neck region. The right subclavian arises from the brachiocephalic trunk, the left from the aortic arch. Because of this, the first part of the right and left subclavian arteries differs both in the origin and length. The branches of the subclavian artery are vertebral artery, internal thoracic artery, thyrocervical trunk, costocervical trunk and dorsal scapular artery. On the left, all branches except the dorsal scapular arise from the first part; on the right, the costocervical trunk usually springs from the second part $^{1,2)}$.

The vertebral artery is the first and largest branch of the subclavian artery. Its extracranial part arises from the superoposterior aspect of the subclavian, usually enters the foramen of sixth cervical transverse processes, rarely the seventh, curves medially behind the lateral mass of the atlas and then enters the cranium via the foramen magnum. Its intracranial part joins its fellow to form the basillar artery at the lower pontine border.

In this study, the variations of the branches of the subclavian arteries in the cadaver of an eighty year-old man were described. On the left side, the vertebral artery arose directly from the aortic arch but on the right side, it was as usual. However on the right side, there was no thyrocervical trunk and the transverse cervical artery arose directly from the subclavian artery. It was also observed the right suprascapular artery began from the internal thoracic artery.
The variations of the subclavian artery and its branches have a great importance both in blood vessels surgery and in angiographic investigations.

\section{Subjects}

This work is based on a dissection carried out in the Department of Anatomy in the Faculty of Medicine of the Çukurova University in 1996-1997 academic year. A dissection was made of neck region of 80 -year-old male cadaver. After seeing variations, the dissection was completed by following the course of the subclavian arteries and their branches.

\section{Findings}

In our case, the left vertebral artery originated from the superior aspect of the aortic arch between the left subclavian artery and the left common carotid artery instead of the left subclavian artery. It first ascended behind the carotid sheath for about $9.5 \mathrm{~cm}$ and then passed through the foramen of fifth cervical vertebra. Thyrocervical trunk arising from the superior aspect of the first part of the left subclavian artery gave off a common trunk. The transverse cervical artery and the suprascapular artery originated from this trunk near the medial border of the scalenus anterior muscle and crossed this muscle anteriorly (Fig. 1.a, b, c). 
On the right side, the vertebral artery arose as usual, but there was no thyrocervical trunk. Two branches originated from the second part of the subclavian artery at a distance of $1 \mathrm{~cm}$ : The first branch, the costocervical trunk, situated medially and it divided into the deep cervical artery as superior branch and the superior intercostal artery as inferior branch (Fig. 2.a, b, c). The lateral branch, the transverse cervical artery, passed deep to the scalenus anterior muscle and inclined laterally toward the posterior cervical triangle.

The main finding is that the suprascapular artery arose from the internal thoracic artery instead of the thyrocervical trunk; it first crossed anterior to the scalenus anterior muscle run parallel to the clavicle behind this bone and then turn backward passing deep to the inferior belly of omohyohid muscle.

\section{Discussion}

The subclavian artery and its branches have many variations in their origin, course, level of ascending and termination in the neck ${ }^{2,3}$. The right subclavian artery may directly arise from the aortic arch or both subclavian arteries may originate from the common trunk arising from the aortic arch.

The variations in the origin and the course of extracranial part of the vertebral artery are also common $^{4-9}$. The vertebral artery may originate from the aortic arch or the left external carotid artery. Atypical artery positions, turtuosity and duplication of the vertebral artery are frequent variations in this artery $4,5,7,10)$. The origin of the vertebral artery directly from the aorta usually occurs on the left and the rate of its incidence has been reported as $2.5 \%$ and $4.5 \%{ }^{1}$.

The frequency of the left vertebral artery arising directly from the aortic arch and following a course between the left common carotid artery and the left subclavian artery is from $1 \%$ to $5 \%{ }^{11,12}$.

The vertebral artery enters the sixth cervical transverse foramen at the rate of $90 \%^{1,9}$. This artery sometimes enters to the fifth cervical transverse foramen. According to Lippert and Pabst ${ }^{11}$, the frequency of this variation is $5 \%$. von Eichhorn ${ }^{13)}$ has suggested that the blood flow factors and ageing may cause the variations of vertebral or basillar artery positions. In our case, the left vertebral artery arose from the aortic arch and entered the fifth cervical transverse foramen.

The suprascapular artery and the transvers cervical artery are normally the branches of thyrocervical trunk. There is no standard pattern for the branching of the transverse cervical artery. Some of its branches may arise separately or as common trunk. These types of branching show an incidence of $50 \%$. In our case, no thyrocervical trunk originating from the subclavian artery on the right side was observed. Two arteries which are normally the branches of the thyrocervical trunk had the unusual origin: a) The transverse cervical artery was a direct branch of the right subclavian artery and b) the suprascapular artery arose from the internal thoracic artery. The frequency of the suprascapular artery arising from the internal thoracic artery has been established at $4.1 \%^{14}$ ). This variation of the suprascapular artery provides a short route to the posterior scapular anastomoses supplying the upper extremity via the internal thoracic artery originated directly from the suprascapular artery. Thus this short route has significant importance because it gives a collateral support to the upper extremity when obstruction or ligation occurs not only in the third part but also in the first part of the subclavian artery. The importance of this case is a cluster of variations of the branches of the subclavian artery was found in one anatomical specimens.

The origin and the course of subclavian artery and its branches, which also supply the brain besides the upper extremity, must be precisely determined for accurate diagnostic interpretation as well as the performance of interventional or surgical procedures such as the construction of a subclaviovertebral bypass, balloon dilatation of subclavian artery stenosis, treatment of aortic coarctation by plasty with the subclavian artery and artery dissection $^{4,15-19)}$.

The variations of the subclavian artery are explained by embryologic development. The early limb bud receives blood via intersegmental arteries which contribute to a primitive capillary plexus. In the upper limb bud the lateral branch of the seventh intersegmental artery usually persists as the subclavian artery. Because of multiple and plexiform sources of this artery, variations such as divergence in the mode and proximodistal level of branching, aberrant vessels connecting other principal vessels are fairly common. The vertebral and internal thoracic artery develop from longitudinal arteries of intersegmented anastomoses. Caudal shifting of the aorta may cause the longitudinal torsion and bending of the proximal parts of segmental arteries by resulting the abnormal connections between the longitudinal arteries and the subclavian artery ${ }^{2)}$. The anomalies found in the subclavian artery may also cause the pathologic conditions. Rodrigez et al. ${ }^{20)}$ reported a case with dysphagia lusoria caused by an abnormal right subclavian artery associated with aortic coarctation. Therefore, the variations as well as physiological 
factors should be considered as causes of certain diseases related to the vessels.

\section{References}

1) Grant JCB. An Atlas of Anatomy. 6th ed. The Williams and Wilkins Co Baltimore 1972; pp. 432-447.

2) Williams PL, Bannister LH, Berry MM, Collins P, Dyson M, Dussek JE and Ferguson MWJ. Gray's Anatomy. 38th ed. Churchill Livingstone, London 1995; pp. 1529-1536.

3) Daseler EH and Anson BJ. Surgical anatomy of the subclavian artery and its branches. Surgery Obstetrics and Gynecology 1959; 108:149-174.

4) Stefanov S. Angiography of certain pathologic forms of the extracranial portion of the vertebral artery. Folia Med (Plovdiv) 1965; 7(4):247-251.

5) Schmidt $H$ and Pfingst $E$. Duplication of the vertebral artery. Fortschr Geb Rontgenstr Nuklearmed 1973; 118(6):636-640.

6) Distelmaier $P$ and Wappenschmidt J. Atypical termination of the vertebral artery and of the inferior posterior cerebellar artery. ROFO Fortschr Geb Röntgenstr Nuklearmed 1976; 124(3):253-256.

7) Huber $G$ and Piepgras U. Origin of the left vertebral artery from the left external carotid artery. ROFO Fortschr Geb Rontgenstr Nuklearmed 1976; 125(1):63-66.

8) Barth H. Pathomorphological studies on the effect of degenerative changes in the area of the lateral cervical spine and the course of the vertebral artery. Zentralbl Neurochir 1985; 46(2):119-125.

9) Tschabitcher M, Fuss FK, Matula C and Klimpel S. Course of the arteria vertebralis in its segment VI from the origin to its entry into the foramen processus transversi. Acta Anat (Basel) 1991; 140(4):373-377.

10) Hauke P. Turtuosity of the carotid and vertebral arteries: angiographic and clinical findings. Otsch Med Wochenschr 1973; 98(50):2381-2384.

11) Lippert $\mathrm{H}$ and Pabst $R$. Arterial variations in man. Classification and frequency. J.F. Bergmann Verlag München 1985.

12) Vorster W, du Plooy PT and Meiring JH. Abnormal origin of internal thoracic and vertebral arteries. Clinical Anatomy 1998; 11:33-37.

13) von Eichhorn $M$. Causes of variations in the pathway of the basilar and vertebral arteries. Gegenbaurs Morphol Jahrb 1991; 136(1):127-134.

14) Bergman RA, Thompson SA, Afifi AK and Saadeh FA. Compendium of Human Anatomic Variation. Urban and Schwarzenberg, Baltimore 1988.

15) Habel J. Radiologic presentation of the vertebral arteries and the right carotid artery by means of direct subclavicular injection of the subclavian artery. J Belge Radiol 1967; 50(3):171-179.

16) Araneda I, Gomez O, Arretz C, Leon L, Eimbcke F and Zilleruelo $\mathrm{R}$. Treatment of aortic coarctation in children by plasty with the subclavian artery. Rev Chil Pediatr 1986; 57(5):401-404.

17) Burger $K$ and Luther $B$. Surgical treatment of extracranial occlusive processes of the vertebral artery by contraction of a subclavio-vertebral bypass. Zentralbl Chir 1989; 114(3): 181-189.

18) Thomassen $\mathrm{L}$ and Krakenes J. Balloon dilatation of subclavian artery stenosis and brachiocephalic trunk stenosis. Tidsskr Nor Laegeforen 1989; 109(10):1063-1068.

19) Frauchiger $B$ and Bernays DR. Spontaneous dissection and stenosis of the vertebral artery. Schweiz Med Wochenschr 1991; $121(35): 1243-1248$.

20) Rodrigez Cuartero A, Rodrigez Cuartero F and Pelaez Redondo J. Dysphagia lusoria, caused by an abnormal right subclavian artery associated with aortic coarctation. Rev Esp Enferm Apar Dig 1979; 55(2):215-222. 
Plate I
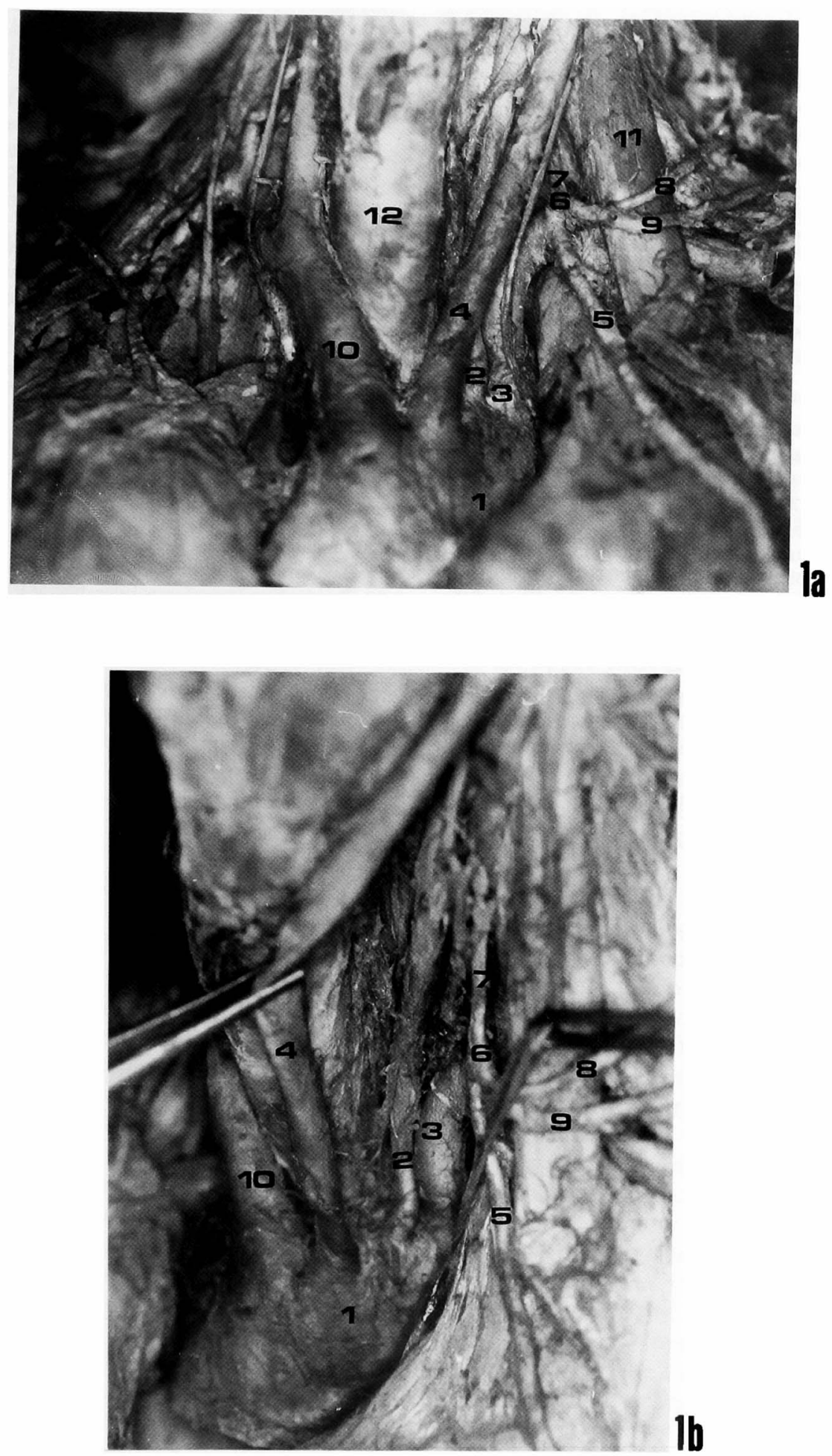


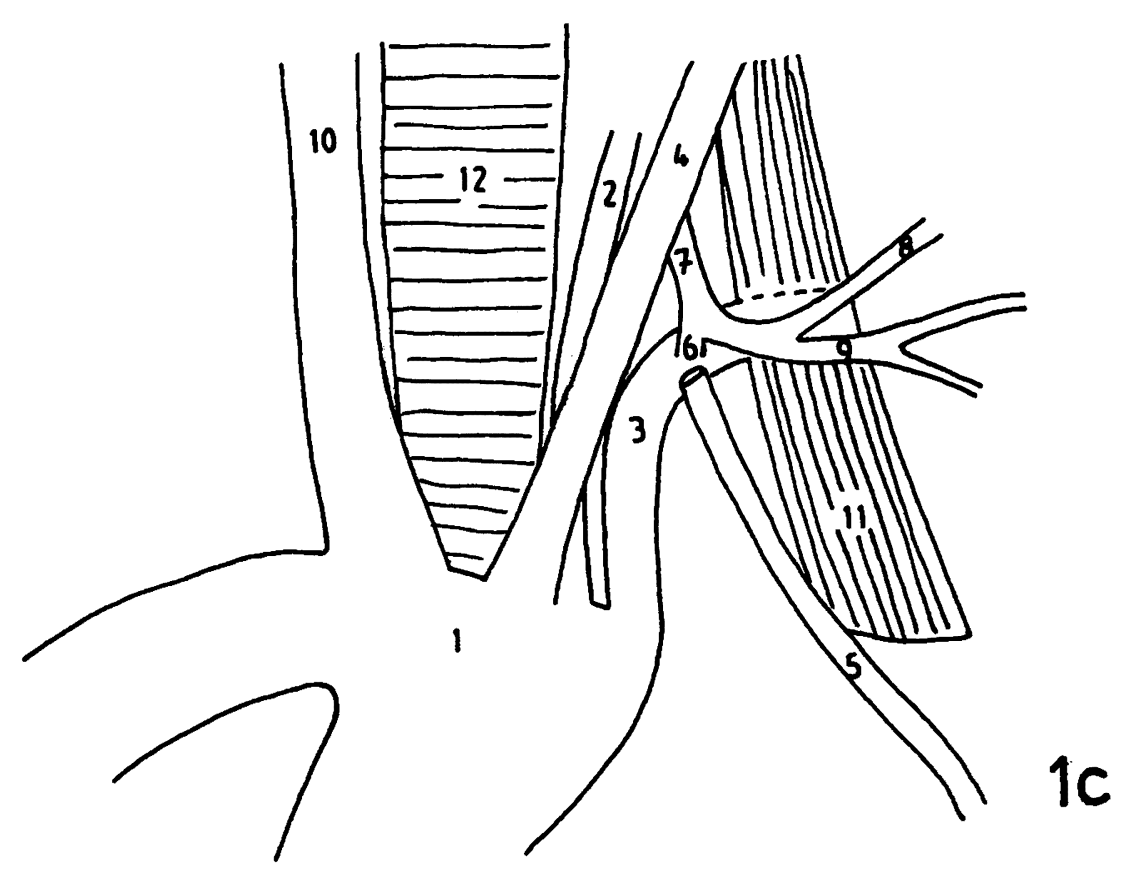

Explanation of Figures

Plate I

Fig. 1.a. The branches arising from the left side of aortic arch. b) The left vertebral artery originated from aortic arch. The left common carotid artery was pulled up to demonstrate the vertebral artery. c) The schematic representation of the left side. 1: Aortic arch; 2: Vertebral artery; 3: Subclavian artery; 4: Common carotid artery; 5: Internal thoracic artery; 6: Thyrocervical trunk; 7: Inferior thyroid artery; 8: Transverse cervical artery; 9: Suprascapular artery; 10: Brachiocephalic trunk; 11: Scalenus anterior muscle; 12: Trachea. 
Plate II
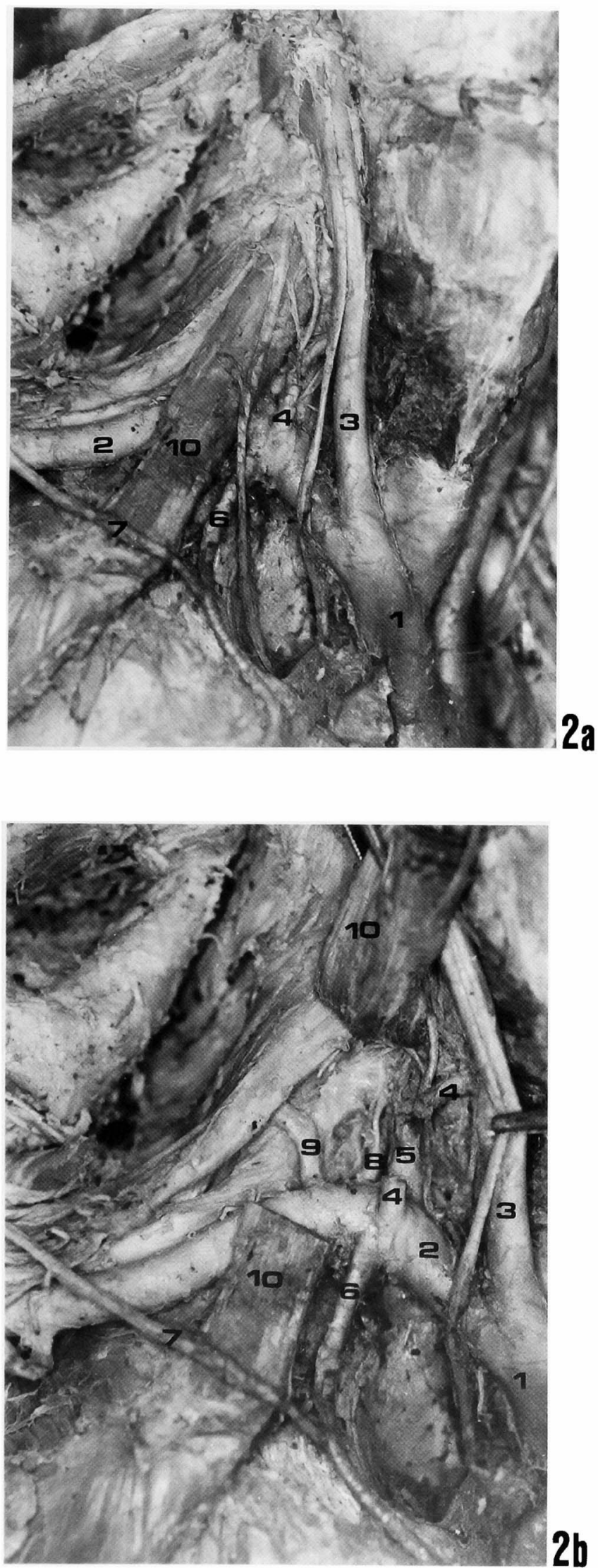


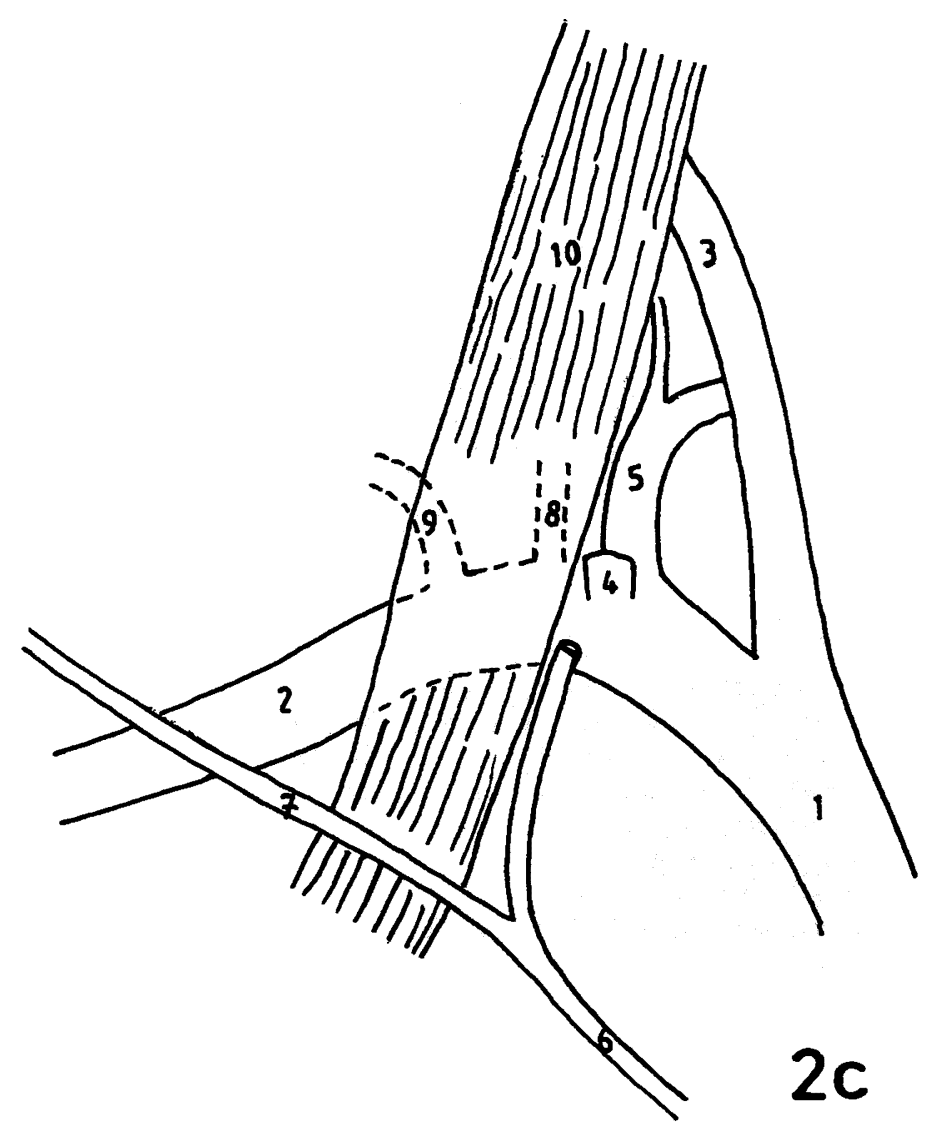

Plate II

Fig. 2.a. The branches arising from the right side of aortic arch. b) The scalenus anterior muscle was dissected and retracted to demonstrate the right subclavian artery and its branches. c) The schematic representation of the right side. 1: Brachiocephalic trunk; 2: Subclavian artery; 3: Common carotid artery; 4: Inferior thyroid artery; 5: Vertebral artery; 6: Internal thoracic artery; 7: Suprascapular artery; 8: Costocervical trunk; 9: Transvers cervical artery; 10: Scalenus anterior muscle. 